\title{
Language Switching in the Production of Phrases
}

\author{
Andrzej Tarlowski · Zofia Wodniecka • \\ Anna Marzecová
}

Published online: 27 March 2012

(C) The Author(s) 2012. This article is published with open access at Springerlink.com

\begin{abstract}
The language switching task has provided a useful insight into how bilinguals produce language. So far, however, the studies using this method have been limited to lexical access. The present study provides empirical evidence on language switching in the production of simple grammar structures. In the reported experiment, Polish-English unbalanced bilinguals switched between their L1 and L2 while describing pictures of ongoing and completed actions with simple SV progressive and perfective phrases. The results show asymmetrical switching costs for progressive phrases and symmetrical switching costs with reversed dominance for perfective phrases. These findings parallel those obtained in tasks requiring the production of single words, although the present study is the first in which the same bilingual participants display different patterns of switching costs depending on the characteristics of utterances they produce. These results can be explained using recently developed models of bilingual language control.
\end{abstract}

Keywords Bilingualism · Language switching - Grammar production · Lexical access

\section{General Introduction}

Managing two languages is a complex cognitive task. When speaking, a bilingual has to be able to select appropriate language. This entails the selection of the appropriate phonological system, lexicon, and grammar. It is remarkable that bilinguals routinely perform this task

A. Tarlowski

The Bilingual Mind Group, University of the Basque Country, Vitoria-Gasteiz, Spain

A. Tarlowski $(\varangle)$

Faculty of Psychology, University of Finance and Management, ul. Pawia 55, 01-030 Warsaw, Poland e-mail: antarlow@gmail.com

Z. Wodniecka · A. Marzecová

Institute of Psychology, Jagiellonian University, Kraków, Poland 
with great accuracy - unintended selection errors being a relatively infrequent occurence in the utterances of proficient bilinguals (Poulisse 1999). One situation that may potentially put great strain on the processing capacity of a bilingual is that of switching between languages. However, bilinguals often switch between their two languages spontaneously, successfully reacting to cues from the environment (Clyne 2003; Gumperz 1982; Myers-Scotton 2005; Owens 2005; Poplack 1980).

The phenomenon of both voluntary and involuntary switching between languages is of interest to experimental psychologists and psycholinguists seeking to develop models of executive control and of the processes responsible for lexical access. One of the main challenges for professionals in these fields, is to gain understanding of the cognitive mechanism that allows bilinguals to effortlessly produce intended language, despite the fact that both of their languages are activated even if only one language needs to be used in a given context (e.g. Colomé 2001; Costa et al. 2000, 2003; De Bot 1992; Gollan and Kroll 2001; Hermans et al. 1998). The problem of switching between languages is also of interest to linguists who construct abstract descriptions of bilinguals' languages (Myers-Scotton 2006). These two traditions differ both in methods and the units of analysis. Psychologists and psycholinguists rely on controlled experiments and study the production of single words, object names or numerals. Linguists study instances of language mixing in samples of speech retrieved from naturally occurring situations and in their analysis, focus most often on syntactic structure.

Recently, there have been attempts to bridge the gap between these different approaches. For example, Myers-Scotton (2006) presented empirically testable questions that arise from linguistic research while, in their recent study, Gollan and Ferreira (2009) modified experimental conditions so that they more closely resembled the circumstances of natural language use. The study reported here also attempts to approximate natural language use in an experimental setting by eliciting the production of grammatical structures. It analyses how bilinguals produce simple sentences, referring to either ongoing or completed actions in a task that requires language switching.

\section{The Experimental Research Relevant to Language Switching in Bilinguals}

Throughout the experimental tradition, language switching tasks have been one of the most productive means of studying bilinguals' lexical access. In their seminal study, Meuter and Allport (1999) asked bilinguals to name numerals in their two languages. The choice of a language depended on an arbitrary cue, that of the color of numerals. During some trials the cue changed, which elicited from the participants a change in the language of naming. Meuter and Allport compared the naming times in the two languages, in trials that did or did not involve participants' switching of language. They found that while switching from one language to another always involved processing cost, this cost was larger when participants switched to their dominant language than when they switched to their weaker language. Meuter and Allport (1999) argued that this counterintuitive result provides strong support to the inhibitory control account of bilingual language selection (Green 1998). The authors claimed that asymmetrical switching cost is observed whenever there is a difference in strength of the two tasks between which the participant alternates (Allport and Wylie 1999). By their account, asymmetrical switching cost results from the interference of the previous task set in response selection. When two responses compete for selection and the intended response is weaker, the stronger, unintended response must be inhibited. The inhibition is reactive: its strength is proportional to the strength of activation of the unintended 
response. This inhibition carries over to a subsequent trial and it needs to be overcome if the subsequent trial requires a previously unintended response. It follows that stronger tasks have to overcome stronger inhibition to be executed during the switch. This is manifested in greater switching costs for stronger than for weaker tasks. Importantly, in the context of language switching, Meuter and Allport's model assumes that the inhibition is language general - that is, it affects each language as a whole, rather than simply affecting individual utterances. Rather than focusing on the properties of individual verbalisations, Meuter and Allport predict the pattern of switching costs directly from the difference in strength between bilinguals' L1 and L2.

Asymmetrical switching costs have been replicated in the literature and proved to be rather robust (e.g. Costa and Santesteban 2004; Costa et al. 2006; Jackson et al. 2001). However, several recent studies question the generality of this effect and thus serve to constrain or challenge Meuter and Allport (1999) account of bilingual language control.

In a study by Costa and Santesteban (2004), asymmetrical switching costs were not observed when highly proficient bilinguals alternated between dominant L1 and somewhat weaker L2 and - even more strikingly — when they alternated between L1 and a much weaker L3. The observed symmetrical switch costs in this group of participants were accompanied by a reverse dominance effect, i.e. longer naming latencies for the stronger language than for L2 or L3 [see also Hernandes and Kohnert (1999) for results showing the lack of asymmetry in highly proficient bilinguals]. Symmetrical switch costs and reverse dominance were also observed in a group of unbalanced German-Dutch bilinguals intensively learning Dutch while studying in the Netherlands (Christoffels et al. 2007). This would suggest that the processes observed by Costa and Santesteban may also operate when bilinguals are in conditions that require intensive use of both languages. Costa and Santesteban (2004) interpret their results by arguing that highly proficient bilinguals may not use inhibitory control when accessing lexical items. An alternative explanation, however, could be that the switch costs are not a reliable source of insight into the inhibitory process involved in bilingual production (Kroll et al. 2008, Wodniecka et al. in prep.).

A recent study by Gollan and Ferreira (2009) showed that asymmetry in the switching cost is not present when unbalanced bilinguals manage the switching themselves. Gollan and Ferreira asked participants to name pictures in whichever language they preferred. Such procedure resulted in a similar pattern to that observed in the group of highly proficient bilinguals studied by Costa and Santesteban (2004). Since participants in Gollan and Ferreira's study were free to choose the language of naming for each item, they tended to produce more frequent, and hence, easier names in L2 and less frequent, and hence, more difficult names in L1. Gollan and Ferreira argued that in their task, participants did not have to apply strong inhibition to L1 in L2 naming trials, because they used L2 only in trials that afforded relatively equal activation of lexical equivalents in both languages. In Gollan and Ferreira's view, the voluntary language switching elicited in this experiment freed participants from the necessity of applying strong L1 inhibition and therefore allowed them to maintain a constant, moderate level of L1 inhibition. In summary then, according to Gollan and Ferreira's account, the existence of asymmetry in language switch costs depends on the relative difference in the level of activation between L1 and L2 lexical items. When L1 lexical items receive far stronger activation than L2 lexical items, speakers need to apply strong L1 inhibition in order to produce L2. This strong level of inhibition needs to then be lifted when participants switch to produce L1. When L1 and L2 lexical items differ only moderately in activation levels, bilinguals can switch between languages flexibly by applying a constant level of inhibition to the slightly stronger language. This account proposes language general inhibition but it is sensitive to the level of activation of individual utterances. 
A serious challenge to the inhibition account of bilingual lexical selection comes from a study by Finkbeiner et al. (2006). In this study, participants alternated between naming numerals and naming pictures or dot patterns. Numerals were bivalent stimuli-they could be named in both L1 and L2 - while pictures or dot patterns were univalent - that is, they were named in L1 only. Finkbeiner et al. compared the three types of L1 responses in a "language switch" and "no language switch" condition. According to the authors, if participants needed to inhibit L1, the switch costs would have been observed in all three conditions. Switching costs were found when participants named bivalent stimuli (i.e. numerals) but not when they named univalent stimuli (i.e. pictures or dot patterns). Additionally, Finkbeiner et al. demonstrated asymmetrical switching cost in a monolingual task by manipulating the speed of word availability. Based on these results, Finkbeiner et al. (2006) rejected the possibility that asymmetrical switching cost is a manifestation of a reactive inhibitory mechanism. They argued instead that the cost is due to the blocking of the undesired response and it is related to the difference in speed of response availability. The response blocking is said to affect responses after they have been selected. Since L1 responses become available very quickly, they are available even before the participant reconfigures the task goal on a switch trial, which makes them susceptible to blocking. Moreover, Finkbeiner et al. argue that the processes that contribute to switching cost are sensitive to the specific properties of individual lexical items (i.e. speed of response availability), rather than the relative strength of bilinguals' two languages, which means that the speed of access to particular lexical items will modulate switching cost regardless of the response language.

Monsell et al. (2000), after reviewing their research on non-linguistic task-switching, concluded that a larger cost of switching to a stronger than to a weaker task is far from being a ubiquitous phenomenon. In fact, in some tasks they demonstrated a reverse asymmetry, i.e. participants taking longer to switch to a weaker than to a stronger task. Monsell et al. argue that the interference from previously applied inhibition is not the only factor that influences the pattern of switch costs. They suggest that the strategy of inhibiting a stronger task is needed when the difference in strength between the two tasks reaches a certain threshold. They also argue that task difficulty is a factor that contributes to switching times because it affects the duration of post-stimulus-onset control processes. Relatively difficult tasks require more time for task set reconfiguration and therefore may take longer to switch into than do easier tasks.

Even this short review of literature demonstrates a considerable diversity in the accounts of processing costs involved in language switching. The explanations invoke various concepts, from inhibitory control, response blocking, to task set reconfiguration. The alternative accounts stress the impact of different factors that seem to influence the pattern of switching costs in language switching tasks; these include the relative activation level of languages (Meuter and Allport 1999; Gollan and Ferreira 2009) or response availability of lexical alternatives in L1 and L2 (Finkbeiner et al. 2006). Additionally, Monsell et al. (2000) propose that the difficulty of task set reconfiguration may be a factor contributing to differences in reaction times.

An important question that arises from the current literature is whether the processes responsible for language switching costs are sensitive to bilinguals' languages in their entirety or whether they are sensitive to the properties of individual utterances, in other words, whether they are language or utterance specific. In Meuter and Allport's study (1999) participants named numerals, which are frequently occurring, easily accessible words. The authors made no explicit predictions regarding the properties of specific lexical items. Similarly, Costa and Santesteban (2004) focused on relative language proficiency rather than within-language variability. Gollan and Ferreira (2009) suggested that word frequency modifies the difference in 
activation of lexical alternatives and hence impacts on the amount of required inhibition. All of these accounts assume that whenever inhibition is applied, it impacts the entire language system. However, Finkbeiner et al. (2006) argue that processes responsible for switching costs are only sensitive to the properties of specific utterances. In order to decide whether the switching costs are sensitive to overall language proficiency or to the characteristics of individual utterances, it is necessary to manipulate the relative activation level or response availability of specific utterances in L1 and L2. One way to approach this issue is to analyse switching cost as a function of cognate status of the words. Cognates differ from noncognates in terms of time of learning or speed of access (Costa et al. 2000; De Groot and Keijzer 2000; Lotto and De Groot 1998). Because cognates are accessed more easily than noncognates, it could be expected that the difference between L1 and L2 lexical equivalents in the level of activation or response availability will be lower for cognates than for noncognates. Two studies that looked at the impact of cognates on switch cost asymmetry failed to show the impact of cognate status on switching performance. Santesteban (2006) tested switching in a task that elicited cognates and noncognates. He replicated the results typical for unbalanced and high-proficient bilinguals but he found no difference in switching costs as a function of cognate status. Also, Christoffels et al. (2007) found no differences in switching costs as a function of cognate status of the word.

In the present study the relative activation level of utterances in L1 and L2 is manipulated by varying the overall difficulty of L2 grammatical structures elicited from participants. Polish-English unbalanced bilinguals ${ }^{1}$ were asked to name actions in progress and completed actions. It could be assumed that, while for native speakers aspectual distinctions have little consequences in terms of processing, for Polish learners English present progressive and present perfective pose markedly different processing demands. As will be explained below, for Polish learners of English, English present progressive is morphologically and conceptually easier to acquire than present perfective. Moreover, Polish speakers acquire English present progressive earlier than they acquire present perfective. These differences may create a situation in which the difference in response availability or activation level between L1 and L2 is larger for perfective than for progressive sentences. It is of interest whether such a difference in L2 grammar processing will be manifested in the conditions of the language switching task. The following sections describe the differences between the production of grammar and lexical access in bilinguals and propose how the construction of aspect in English and Polish may influence aspect processing in Polish-English bilinguals' L1 and L2. Predictions are then formulated concerning processing costs in a language switching task involving the production of progressive and perfective phrases. This is done with reference to current models of bilingual language processing.

\section{Production of Single Lexical Items and Production of Grammatical Structures}

Previous experimental research on language switching has focused on the production of nouns and numerals. The present procedure diverges from this practice by looking at the production of verbs within grammatical structures. First of all, the production of verbs differs markedly from the production of nouns. Szekely et al. (2002) found important differences between naming objects and naming actions that could not be reduced to differences in

\footnotetext{
1 Although the distinction between highly proficient and unbalanced bilinguals is a matter of degree, people who were not exposed to their second language in early childhood, learned their second language at school rather than through immersion, and report significantly lower level of command for their second language than for their native language may be considered as unbalanced bilinguals.
} 
word frequency, age of acquisition, or image complexity. Overall, naming actions was more difficult, which was reflected by longer RTs and lower name agreement.

Moreover, producing grammatical structures differs from producing isolated lexical items. As far as RT data, the differences in producing words and grammatical structures are not clearly apparent. Kempen and Huijbers (1983) compared the production of subjects and verbs, as well as simple sentences (both SV and VS). They found that the production of subjects was considerably faster than that of verbs and phrases, while there were no differences between the production of verbs and that of the two types of phrases. They argued that in the production of phrases, pre-phonological lexical items corresponding to the subject and verb are retrieved simultaneously, but the phonological encoding, which is serial, can only begin once all pre-phonological lexical items have been retrieved. Provided that phonological encoding times for verbs and subjects are comparable, due to simultaneous retrieval of pre-phonological forms, overall production latencies should depend on the lexical item whose pre-phonological form takes longest to retrieve, rather than on the number of items to be retrieved. As the process of verb retrieval takes longer than that of subject retrieval, Kempen and Huijbers (1983) model suggests that in terms of RT, generating simple descriptions should not differ significantly from generating verbs.

The models of bilingual grammar production assume that lexicon and grammar rely on separate sets of processes (Hartsuiker and Pickering 2008). According to Ullman (2001), grammar processing is subserved by a procedural system while processing lexicon is subserved by a declarative, associative system. The inclusion of L2 grammar into a procedural system depends on both the age of acquisition and frequency of use. If a particular L2 grammatical structure is acquired late and is not frequently used, it may be processed in a declarative fashion. This proposal is supported by neurolinguistic data, showing that localisation of lexicon depends on proficiency level, while localisation of syntax depends on age of acquisition (Wartenburger et al. 2003). Clahsen and Felser (2006) argue that L2 processing can become native-like in some linguistic sub-domains (including certain aspects of grammar), but that L1/L2 processing differences persist in the domain of complex syntax, even in highly proficient L2 speakers. Based on such a claim, it can be argued that L2 grammatical structures may differ in processing cost and speed of availability. Such differences should not be seen in L1 grammatical structures.

\section{Aspect}

Aspect is a grammatical category that yields favourable conditions for testing the role of variability in both the processing cost and speed of availability of L2 grammatical structures in the context of language switching. Aspectual distinctions are orthogonal to the time reference of the sentence and they reflect the speakers' perspective of the action. Aspect marks whether the action is portrayed as completed or in progress (Quirk et al. 1985). In Polish, aspectual distinctions are expressed by verb morphology. Most verbs are marked for aspect. The rules of aspectual marking are quite complex; many progressive verbs have the form of simple unprefixed imperfective stems, but some progressive verbs are prefixed imperfective stems augmented by a suffix (Zagorska Brooks 1975). In English on the other hand, aspect is expressed syntactically. Both aspects are marked by the use of complex verbs. Progressive aspect is composed of the auxiliary be and the present participle. Perfective requires the auxiliary have and past participle (Quirk et al. 1985). Because of cross-linguistic differences in the way aspectual information is expressed in a language, for Polish learners of English, English perfective and progressive forms pose rather different challenges in terms of 
morphology and semantics. Polish does not express the English present perfective meaning of past time with current relevance. This meaning is quite difficult to grasp for Polish learners, who typically have trouble differentiating English present perfective from past simple. Polish perfective verbs never express a present tense (perfective verbs conjugated according to present tense carry future meaning). English present progressive, on the other hand, is much easier to comprehend because it taps a conceptually salient set of actions in progress and it overlaps with the meaning of Polish primary imperfectives (Polish has a rough division between primary imperfectives such as pije [is drinking] which mark actions in progress, and secondary imperfectives which are frequentative, e.g. pija [drinks]). The formation of English present and past participle also pose different challenges to Polish learners. The formation of present participle relies on a compositional rule of adding the suffix -ing, to which there are no exceptions. The majority of past participles are formed by adding the suffix -ed to a verb stem, but many high frequency verbs are irregular.

Both conceptual and morphological differences between present progressive and present perfective result in differences in difficulty of acquisition. It is therefore much easier for Polish speakers to learn English present progressive than present perfective (see Buczowska and Weist 1991; Hinkel 1992 for difficulties in fixing present perfect time reference in English as a second language learners). The apparent difference in the level of difficulty between these aspects is reflected in the fact that most curriculums of English as a foreign language introduce present progressive much earlier than they introduce present perfective. For example, a primary school English coursebook 'Way Ahead' (Bowen and Ellis 2008) introduces the present continuous in Unit 16 of Book 2 while it introduces the present perfect in Unit 12 of Book 4, which suggests a 2-year gap between the two aspects for this coursebook. Based on the comparison of the grammatical structures expressing aspect in English, it can be assumed that Polish speakers have more difficulty producing English perfective than progressive, due to factors including differences in age of acquisition, frequency of use, rule complexity and conceptual difficulty.

\section{Predictions}

In the present study, Polish-English unbalanced bilinguals viewed pictures of ongoing and completed actions and then produced descriptions of these actions in their L1 and L2.

If processing grammatical structures puts different constraints on language switching behaviour than do the processes involved in simple lexical access, the findings of this study should diverge from those previously obtained through using noun or numerals production. One factor that may come into play in a paradigm which requires participants to switch languages in producing grammar, is task set reconfiguration (Monsell et al. 2000). The length of time needed for task set reconfiguration does not seem to affect bilinguals' performance in language switching tasks where single words are elicited. This is probably because the act of reconfiguring in order to use their weaker language does not require a long enough time to produce reverse asymmetry. However, when bilinguals switch languages in producing grammatical structures, task set reconfiguration may play a role. As has been argued above, for some L2 grammatical structures, grammatical encoding may proceed in declarative fashion and may therefore require a relatively longer time period. If the same structure is produced in subsequent L2 trials, the production of this structure should be facilitated by virtue of syntactic priming (Pickering and Branigan 1999). However, when participants switch to L2, they have to reconfigure the task set and the lengthy process of grammatical encoding has to be initiated anew. In such cases, based on the assumption that English perfective is particularly 
difficult for Polish speakers to produce, reversed asymmetry in naming completed actions could be expected (switching to English would be more costly than switching to Polish).

If, however, the production of grammatical structures in a language switching task resembles the production of nouns and numerals, an alternative set of results than those outlined above would be likely to emerge. If the processes responsible for switching costs are only sensitive to overall language proficiency, an asymmetrical switching cost would be observed for both progressive and perfective structures. On the assumption that the only factor that has an impact on the pattern of switching costs is language proficiency (or more specifically, the difference in strength between L1 and L2) irrespective of grammatical structures, longer naming latencies would be associated with switching to dominant Polish than with switching to weaker English, given that the participants in the reported study are unbalanced bilinguals. If, however, the processes involved in bilinguals' language switching are sensitive to the properties of individual utterances (as argued by Finkbeiner et al. 2006), a dissociation between the results for progressive and perfective sentences could be expected. It is assumed here that for Polish-English unbalanced bilinguals, English progressive should require less processing and should be faster to produce than English perfective. It is also assumed that there are no processing or speed of access differences between aspects in these bilinguals' L1. Overall, the level of activation and speed of access is higher for L1 than L2 so it could be expected that the disparity in the level of activation and speed of access between L1 and L2 would be greater for perfective than for progressive sentences.

The predictions derived from Finkbeiner et al. (2006) are based on the difference in timing of response availability between L1 and L 2 for the two aspects. Relatively low L1-L2 disparity in response availability for progressive sentences would result in symmetrical switching cost. When L1 and L2 structures become available at roughly the same time, as may be the case for progressive structures, L1 should not be blocked more frequently at switch trials than L2. When L1 structures become available much earlier than L2 structures, L1 structures may be blocked more frequently at switch trials than L2 structures, which would lead to switch cost asymmetries.

According to Gollan and Ferreira (2009) account, large differences between L1 and L2 in levels of activation force bilinguals to apply strong L1 inhibition when they produce L2 and to lift this inhibition when they produce L1. This strategy should result in switching cost asymmetry. As the L1-L2 disparity in activation level decreases, bilinguals become better able to apply constant inhibition to L1 in order to equate the activation levels. Such a strategy is manifested by reversed dominance and symmetrical switching costs. In the present study, it can be predicted that constant L1 inhibition would more likely be applied for progressive sentences due to relatively low L1-L2 activation disparity. For perfective sentences, bilinguals would be more likely to apply and lift strong L1 inhibition since L1-L2 activation disparity should be relatively high. This results in an expectation of larger asymmetries for perfective than for progressive and reversed dominance for progressive sentences.

\section{Method}

\section{Participants}

Eighteen native speakers of Polish with medium to high proficiency in English took part in the study. Four participants were excluded from the data analysis (see "Results" section). The demographic and language proficiency data presented below correspond to the 14 participants whose responses were included in the final analysis. The mean age of those tested was 
21.4 years (SD 2.44 years). Three of the participants were men. Each individual filled out a self-assessment language proficiency questionnaire probing various aspects of language proficiency on a seven point scale. The assessment included proficiency in understanding, reading, speaking, and writing. Participants also indicated the age at which they began to learn the languages and estimated the percentage of daily use. The average self-rated proficiency for Polish was 6.98 (SD 0.07), while for English it was 5.45 (SD 0.74) $(\mathrm{t}(13)=$ 8.16, $p<0.001$ ). The self-rated percentage daily use for Polish was $77 \%$ (SD 12\%) and for English $20 \%$ (SD $11 \%)(\mathrm{t}(13)=9.03, p<0.001)$. Participants began acquiring Polish from birth, while they began learning English at an average age of 10.9 years (SD 3.5). Data on participants' knowledge of languages other than Polish and English were also collected. The average proficiency level for a third language was 3.2 (significantly lower than English, $\mathrm{t}(13)=6.66, p<0.001)$ and the maximum proficiency level for L3 reached 5.25.

Materials and Procedure

Participants were presented with a series of pictures depicting completed actions or actions in progress (see Fig. 1 for example pictures and Table 1 for the list of all actions used in the study). They were asked to describe the picture in either Polish or English according to an auditory cue, which was the word "What?" for English or its Polish equivalent "Co?". The cues correspond to the interrogatives used in questions that elicit descriptions of pictures: "What is happening? What has happened? Co się dzieje? Co się stało?" Verbal, nonarbitrary
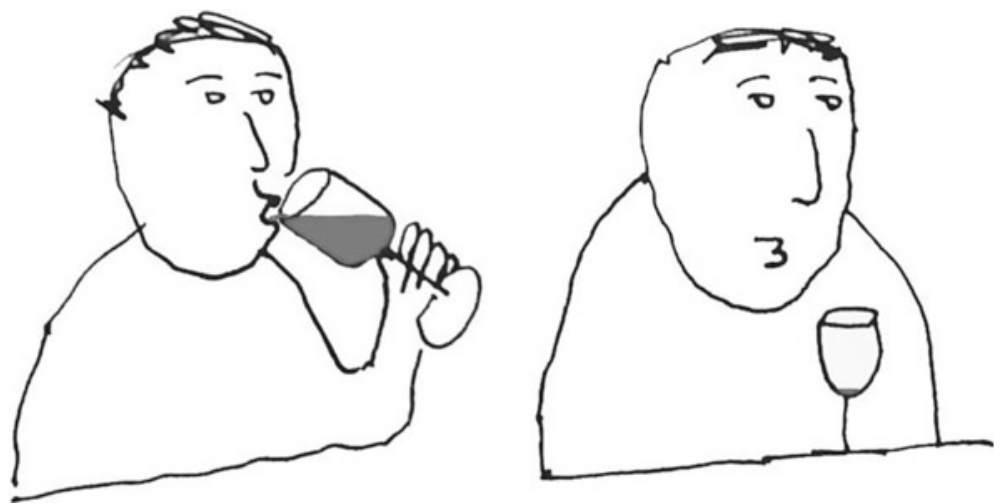

Fig. 1 Images corresponding to drinking in progress and completed

Table 1 Actions used in the study and corresponding progressive and perfective descriptions in Polish and English

\begin{tabular}{llllll}
\hline Infinitive POL & Infinitive ENG & Progressive POL & Progressive ENG & Perfective POL & Perfective ENG \\
\hline Pić & To drink & On pije & He's drinking & On wypił & He has drunk \\
Jeść & To eat & On zjada & He’s eating & On zjadł & He has eaten \\
Ciạć & To cut & On tnie & He's cutting & On przeciął & He has cut \\
Budować & To build & On buduje & He's building & On zbudował & He has built \\
Pisać & To write & On pisze & He’s writing & On napisał & He has written \\
Palić & To smoke & On pali & He’s smoking & On wypalił & He has smoked
\end{tabular}


cues were used in order to make the task more natural. Before the tasks began, participants named the pictures with an experimenter in order to elicit the expected kind of description. The descriptions contained an actor and an action but they did not contain an object. The actor was always the same, so each sentence started with a pronoun, "he" in English and "on" in Polish.

The presentation of pictures showing ongoing and completed actions was blocked. Pictures of ongoing actions elicited progressive sentences and pictures of completed actions elicited perfective sentences. There were 192 trials in total, with 96 constituting the ongoing (progressive) block and the other 96 constituting the completed (perfective) block. Each participant completed both blocks with a short break in-between. The order of presentation of blocks was counterbalanced. The first response in each block was excluded from the analyses. $51 \%$ of trials involved switching the language of response (switch trials). In the rest of the trials participants had to maintain the language of response (no switch trials). Participants were cued to describe half of the pictures in Polish and the other half in English. This design resulted in the three within-subject variables, i.e. type of trial (language switch vs. no language switch), language of naming (English vs. Polish), and aspect (progressive vs.perfective). Four orders of presentation were generated by counterbalancing the order of aspect blocks and the language of naming in a pseudo-random sequence of pictures. No repetition of any picture was allowed from one trial to another.

Before beginning the test proper, each participant completed a training phase which consisted of 40 trials, 20 in the perfective block and 20 in the progressive block. The training used the same set of pictures as the test.

The stimuli were administered by DMDX display software on a PC computer with $2 \mathrm{GHz}$ CPU and 4GB RAM. Each trial commenced with an auditory cue lasting $375 \mathrm{~ms}$. Following the cue, the picture was presented and the program started sound recording. Each image remained on the screen for $2,500 \mathrm{~ms}$. Trials were separated by a $1,000 \mathrm{~ms}$ gap. Reaction times were recorded by the DMDX voice key function and manually checked for correctness. Polish and English sentences differed in the onset phoneme. All English utterances started with a voiceless fricative [h] while Polish sentences started with the vowel [o]. Fricatives are challenging for voice recognition software. For this reason all the data were thoroughly reviewed manually by one of the authors. An independent coder reviewed $10 \%$ of the material. For utterances in Polish the mean difference between the two coders was $1.0 \mathrm{~ms}$ (SD 3.58 ) and the mean absolute difference was $2.1 \mathrm{~ms}$. (SD 3.06). For utterances in English the mean difference between the two coders was $-1.7 \mathrm{~ms}$ (SD 5.95) and the mean absolute difference was $4.7 \mathrm{~ms}$. (SD 4.03). Any error of measurement caused by the difference between the initial Polish and English phoneme could have affected the comparisons between the latencies for Polish and English, but it would not have influenced variables of aspect and type of the trial.

\section{Results}

Long pauses separating words, repairs, wrong language, and nonresponses were considered errors and excluded from the analysis. Following Meuter and Allport's (1999) approach, trials following errors and trials following responses that exceeded 2,000 ms were removed. RTs above 3 SD from participants' mean were removed. For 4 participants the number of eliminated trials exceeded $50 \%$. These participants were excluded from the analysis. In the sample of 14 participants whose responses were analysed, $18.6 \%$ of trials were eliminated 
from RT analysis. $8.7 \%$ of these were errors, the rest were outliers and responses following errors or outliers.

By-participant and by-item proportions of errors and mean reaction times in eight experimental conditions (type of trial by language by aspect) were included in the analysis. By-item analysis was performed to ensure that the observed patterns are stable across items and that they are not a result of idiosyncratic effects specific to individual items. The initial analysis of descriptive statistics showed that by-participant and by-item proportions of errors were significantly skewed. To eliminate skewness the proportions of errors in eight experimental conditions were rank-ordered for each individual participant and each individual item. The rank error data had symmetrical distributions and they were entered into by-participant (F1) and by-item (F2) ANOVAS. The distributions of mean reaction times did not reveal significant skewness and consequently they were directly entered into by-participant (F1) and by-item (F2) ANOVAs.

\section{Accuracy}

The mean error rates are presented in Fig. 2. The $2 \times 2 \times 2$ ANOVA (with type of trial, language of naming and aspect as within-subject factors) yielded a main effect of type of trial. Participants committed more errors when they were switching language than when they were maintaining the language, F1 $(1,13)=34.93, p<0.001$, partial $\eta^{2}=0.73$; F $2(1,5)=$ $120.57, p<0.001$, partial $\eta^{2}=0.96$. There was also a language by type of trial interaction, significant only by participants, $\mathrm{F} 1(1,13)=11.66, p<0.01$, partial $\eta^{2}=0.47$; F2 $(1,5)=$ $2.78, p=0.16$, partial $\eta^{2}=0.36$. Overall, switching to English was associated with greater increase of error rate than switching to Polish. This effect was modified by language by type of trial by aspect interaction, $\mathrm{F} 1(1,13)=4.79, p<0.05$, partial $\eta^{2}=0.27, \mathrm{~F} 2(1,5)=19.03$, $p<0.01$, partial $\eta^{2}=0.79$. In the perfective condition, there was no difference between the languages in the increase of error rate due to switching, $\mathrm{F} 1=1.27$, ns. and F2 $<1$. In the progressive condition, switching to English was associated with a much greater increase in error rate than switching to Polish, F1(1.13) $=13.05, p<0.01$, partial $\eta^{2}=0.50 ; \mathrm{F} 2(1,5)$ $=14.70, p<0.05$, partial $\eta^{2}=0.75$, because in the Polish progressive, the error rate was high both in switch and no switch trials.

\section{Reaction Time Analysis}

The mean reaction times are presented in Fig. 3. The $2 \times 2 \times 2$ ANOVA (with type of trial, language of naming and aspect as within-subject factors) yielded a main effect of language, F1 $(1,13)=35.49, p<0.001$, partial $\eta^{2}=0.73$; F2 $(1,5)=21.72, p<0.01$, partial $\eta^{2}=0.81$. Participants took longer to describe pictures in their native language, Polish, than in their L2, English. There was also a main effect of type of trial, F1 $(1,13)=33.80$, $p<0.001$, partial $\eta^{2}=0.72 ; \mathrm{F} 2(1,5)=25.28, p<0.01$, partial $\eta^{2}=0.84$. Maintaining the language of naming was easier than switching to a different language. Additionally, there was a main effect of aspect significant only in by-item analysis, $\mathrm{F} 2(1,5)=6.67, p<0.05$, partial $\eta^{2}=0.57$ with perfective descriptions taking longer to produce. There was a by-participant interaction between language and type of trial, $\mathrm{F} 1(1,13)=6.93, p<0.05$, partial $\eta^{2}=0.35$; $\mathrm{F} 2(1,5)=3.85, p=0.11$, partial $\eta^{2}=0.44$. The cost of language switching was larger in Polish than in English. There was a by-participant interaction between language and aspect, $\mathrm{F} 1(1,13)=22,45, p<0.001$, partial $\eta^{2}=0.61 ; \mathrm{F} 2(1,5)=3.39, p=0.13$, partial $\eta^{2}=0.40$. In English, naming completed actions took longer than naming actions in progress. In Polish there was no RT difference between aspects. Importantly, these effects were modified by a 

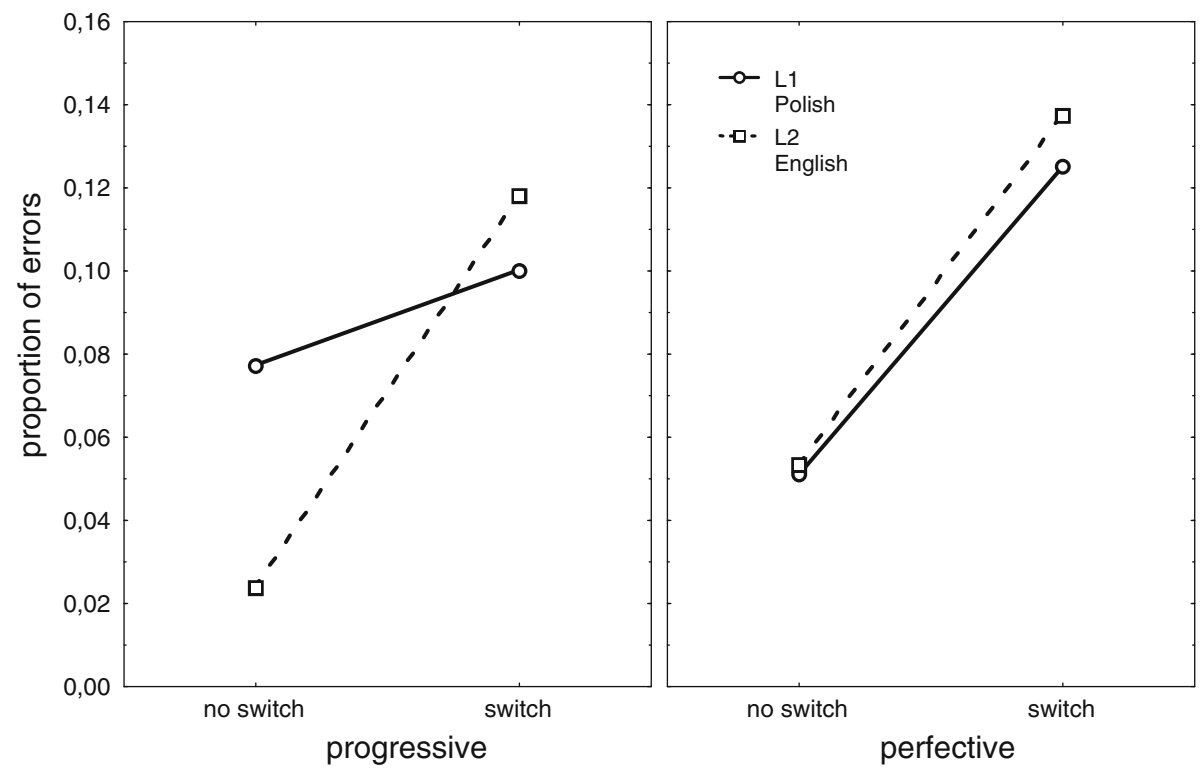

Fig. 2 Proportion of errors by language, type of trial, and aspect

three-way interaction between language, type of trial and aspect, $\mathrm{F} 1(1,13)=6.18, p<0.05$, partial $\eta^{2}=0.32 ; \mathrm{F} 2(1,5)=114.43, p<0.001$, partial $\eta^{2}=0.96$. The asymmetry between L1 and L2 in switch cost was only present in perfective sentences and not in progressive sentences. Separate analyses for the two aspects showed a language by type of trial interaction for perfective, F1 $(1,13)=12.91, p<0.003$, partial $\eta^{2}=0.50 ; \mathrm{F} 2(1,5)=20.48, p<0.01$, partial $\eta^{2}=0.80$, but not for progressive sentences $\mathrm{F} 1<1, \mathrm{~F} 2=1.43, p>0.2$.

The results concerning switch costs in the two aspects are consistent across participants and items. In the perfective condition, 12 participants had a higher switching cost for Polish than for English, while 2 showed a reverse tendency, the distribution consistent with asymmetrical switch cost pattern. As far as individual item patterns are concerned, asymmetry with higher L1 costs was observed for all six experimental items. In the progressive condition, 8 participants had higher switching cost for Polish than for English, while 6 showed the opposite tendency, consistent with symmetrical switch cost pattern. Switching cost was higher for Polish than for English for one item. The reverse was true for three items and for the remaining two items the differences were virtually indistinguishable (less than $5 \mathrm{~ms}$ ).

\section{Discussion}

In this study, Polish-English unbalanced bilinguals switched between their two languages in a task that required them to describe pictures of ongoing and completed actions. The patterns of RTs elicited by this task closely correspond to those obtained in previous research for individual lexical items (Costa and Santesteban 2004; Finkbeiner et al. 2006; Gollan and Ferreira 2009; Meuter and Allport 1999).

Describing ongoing actions was accompanied by symmetrical switching cost and a reversal of dominance: switching to the dominant language was as costly as switching to the 

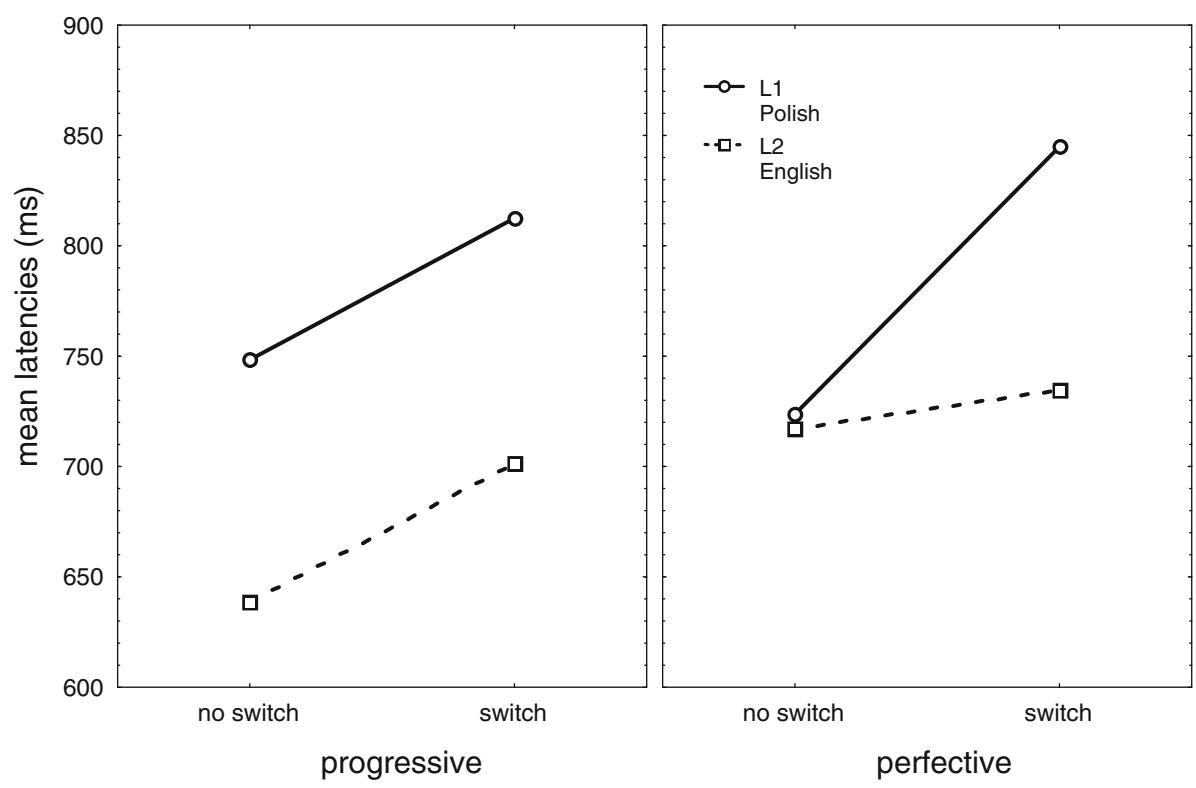

Fig. 3 Mean reaction times by language, type of trial, and aspect

weaker language, but naming actions in the dominant language was on average more costly than in the weaker language. This result parallels the findings obtained by Costa and Santesteban (2004) for high-proficient bilinguals switching between their L1 and L2 or between L1 and much weaker L3. It also resembles the performance of unbalanced bilinguals in a spontaneous switching task observed by Gollan and Ferreira (2009) and the performance of L2-immersed unbalanced bilinguals tested by Christoffels et al. (2007).

The naming of completed actions, however, produced a markedly different pattern of results. In this condition, participants demonstrated an asymmetrical switching cost: it was more costly to switch to the dominant Polish than to weaker English. Such a pattern of results replicates the results of unbalanced bilinguals in Meuter and Allport (1999) study, as well as those in Costa and Santesteban (2004).

Overall, these results clearly show that the same bilingual participants display different patterns of switching costs depending on the characteristics of utterances they produce. Before these results can be interpreted it is necessary to evaluate the initial predictions concerning the processing of aspects in L1 and L2.

The present experimental design was based on the assumption that there are processing differences between grammatical structures expressing progressive and perfective aspect in L2 but not in L1. More specifically, it was assumed that for Polish-English unbalanced bilinguals it would be equally demanding to produce Polish perfective and progressive, while they would find it more difficult to produce English perfective than English progressive. These initial predictions have been borne out by the results. The interaction between language and aspect resulted from the lack of significant RT difference between progressive and perfective in Polish and significantly longer RTs for English perfective than English progressive. The same pattern of results was observed when only no switch trials were analyzed $(\mathrm{t}(13)=$ -1.32 , ns for Polish and $\mathrm{t}(13)=3.9, p<0.01$, two-tailed, for English). 
The results obtained show clearly that task set reconfiguration processes as proposed by Monsell et al. (2000) have no visible effect on switching costs in a task requiring the production of simple phrases. English perfective, being the most difficult to produce, was not the most difficult to switch to. On the contrary, the switching cost for English perfective was marginally lower than the switching cost for English progressive $(\mathrm{F}(1,13)=3.73, p=$ 0.075 , partial $\eta^{2}=0.22$ ). Additionally, the switching cost for (more difficult) English structures was not greater than the switching cost for (easier) Polish structures. In fact it was the reverse.

When looking at the results from the viewpoint of level of activation hypothesis, it was assumed that for Polish-English unbalanced bilinguals, the English progressive form receives stronger activation than the English perfective, while there is no difference between the two grammatical structures in Polish. This creates larger L1-L2 activation disparity for perfective than for progressive descriptions. According to Gollan and Ferreira (2009), when the difference in activation level between bilinguals' two languages is relatively small, a strategy of constantly inhibiting L1 becomes available. The use of this strategy may result in reversed dominance and symmetrical switching costs. Growing disparity between L1 and L2 in activation levels compels the bilingual to apply strong L1 inhibition to produce L2. This level of inhibition cannot be maintained when producing L1. Such constant application and lifting of strong inhibition results in asymmetrical switching costs. The results observed in the present study are in full agreement with Gollan and Ferreira's logic, since reversed dominance and symmetry was observed for the progressive phrases, while asymmetry was observed for perfective phrases.

Under the Finkbeiner et al. (2006) account, the observed asymmetry for perfective and the lack of asymmetry for progressive phrases could be explained in terms of speed of response availability. L1 progressive and perfective are fully automatic and there is no difference in how quickly they become available. However, for Polish native speakers, English progressive becomes available faster than English perfective. The large difference in response availability between Polish perfective and English perfective may, therefore, account for the asymmetry observed in switching cost. In this regard, the results of our study parallel the data from the Finkbeiner et al. (2006) experiment 3, in which participants showed switching asymmetry when the task involved the production of fast (frequent) and slow (infrequent) words. In the case of progressive, the difference in response availability between L1 and L2 may not be sufficient to produce the asymmetry in switching cost. The Finkbeiner et al. account however, cannot explain the reversed dominance effect observed. In the progressive condition, participants took longer to describe pictures in Polish than in English and they had a high rate of errors in Polish, both in switch and in no switch trials. If the switching costs were related to response availability, this should yield faster RTs for L1 descriptions in no switch trials because L1 structures are assumed to be available earlier.

The final issue that needs to be addressed concerns error rates. Participants committed a relatively large number of errors and the proportion of errors dramatically increased for switch trials compared to no switch trials. This finding is not surprising when taking into account the fact that the production of phrases is more complex, and therefore more error prone than the production of single words. One result, though, was unexpected. While the error rate in no switch trials for English and Polish perfective and English progressive did not exceed $5 \%$, for Polish progressive it reached almost $8 \%$. This increase resulted in a significant language by aspect by type of trial interaction. One way to account for this unexpected finding is to refer to Gollan and Ferreira (2009) model, according to which for low L1-L2 disparity in activation, L1 is constantly inhibited. This constant inhibition could result in an increase of error rate for Polish progressive no switch trials. 
To summarise, the present research extends the empirical base for experimental language switching research by investigating bilinguals' switching performance in the production of simple phrases. The results show that there are important parallels between processing single words and phrases by bilinguals. They are consistent with the variant of inhibition model proposed by Gollan and Ferreira (2009) and they are partially consistent with the response blocking model proposed by Finkbeiner et al. (2006). Importantly, the present findings suggest that the overall proficiency level is not the only factor that influences switching behaviour. Apart from overall proficiency, within-language variability, and more specifically, variability in L2 grammar processing difficulty may cause the same speaker to perform as a balanced or unbalanced bilingual. Finally, the present results show that simple phrases can be reliably studied in a language switching paradigm which opens new perspectives for the experimental research of bilingual language control.

Acknowledgments This Project was financed from the CONSOLIDER-INGENIO 2010 Programme CSD 2007-00012 and Polish Ministry of Science and Education Grant H01F03829 and a subsidy from Foundation for Polish Science to Zofia Wodniecka and Anna Marzecová. The authors thank Marianna Boros and Aleksandra Szyper for their help in data collection and Mikel Santesteban for comments on the manuscript.

Open Access This article is distributed under the terms of the Creative Commons Attribution License which permits any use, distribution, and reproduction in any medium, provided the original author(s) and the source are credited.

\section{References}

Allport, A., \& Wylie, G. (1999). Task-switching: Positive and negative priming of task-set. In G. W. Humphreys, J. Duncan, \& A. M. Treisman (Eds.), Attention, space and action: Studies in cognitive neuroscience (pp. 273-296). Oxford: Oxford University Press.

Bowen, M., \& Ellis, P. (2008). Way ahead. A foundation course in English. Books 2 and 4. Oxford: McMillan.

Buczowska, E., \& Weist, R. M. (1991). The effects of formal instruction on the second-language acquisition of temporal location. Language Learning, 41, 535-554.

Christoffels, I. K., Firk, C., \& Schiller, N. O. (2007). Bilingual language control: An event-related brain potential study. Brain Research, 1147, 192-208.

Clahsen, H., \& Felser, C. (2006). Grammatical processing in language learners. Applied Psycholinguistics, 27, 3-42.

Clyne, M. (2003). Dynamics of language contact. Cambridge, England: Cambridge University Press.

Colomé, A. (2001). Lexical activation in bilinguals' speech production: Language-specific or languageindependent? Journal of Memory and Language, 45, 721-736.

Costa, A., \& Santesteban, M. (2004). Lexical access in bilingual speech production: Evidence from language switching in highly proficient bilinguals and L2 learners. Journal of Memory and Language, 50, 491-511.

Costa, A., Caramazza, A., \& Sebastián-Gallés, N. (2000). The cognate facilitation effect: Implications for models of lexical access. Journal of Experimental Psychology: Learning, Memory, and Cognition, 26, 1283-1296.

Costa, A., Colomé, A., Gómez, O., \& Sebastián-Gallés, N. (2003). Another look at cross-language competition in bilingual speech production: Lexical and phonological factors. Bilingualism: Language and Cognition, 6, 167-179.

Costa, A., Santesteban, M., \& Ivanova, I. (2006). How do highly proficient bilinguals control their lexicalization process? Inhibitory and language-specific selection mechanisms are both functional. Journal of Experimental Psychology: Learning, Memory, and Cognition, 32, 1057-1074.

De Bot, K. (1992). A bilingual production model: Levelt's speaking model adapted. Applied Linguistics, $13,1-24$.

De Groot, A. M. B., \& Keijzer, R. (2000). What is hard to learn is easy to forget: The roles of word concreteness, cognate status, and word frequency in foreign language vocabulary learning and forgetting. Language Learning, 50, 1-56. 
Finkbeiner, M., Almeida, J., Janssen, N., \& Caramazza, A. (2006). Lexical selection in bilingual speech production does not involve language suppression. Journal of Experimental Psychology: Learning, Memory, and Cognition, 32, 1075-1089.

Gollan, T. H., \& Ferreira, V. S. (2009). Should I stay or should I switch? A cost-benefit analysis of voluntary language switching in young and aging bilinguals. Journal of Experimental Psychology: Learning, Memory, and Cognition, 35, 640-665.

Gollan, T. H., \& Kroll, J. F. (2001). Bilingual lexical access. In B. Rapp (Ed.), The handbook of cognitive neuropsychology: What deficits reveal about the human mind (pp. 321-345). Philadelphia, PA: Psychology Press.

Green, D. W. (1998). Mental control of the bilingual lexicosemantic system. Bilingualism: Language and Cognition, 1, 67-81.

Gumperz, J. J. (1982). Discourse strategies. Cambridge, England: Cambridge University Press.

Hartsuiker, R. J., \& Pickering, M. J. (2008). Language integration in bilingual sentence production. Acta Psychologica, 128, 479-489.

Hermans, D., Bongaerts, T., de Bot, K., \& Schreuder, R. (1998). Producing words in a foreign language: Can speakers prevent interference from their first language? Bilingualism: Language and Cognition, 1, 213-230.

Hernandes, A. E., \& Kohnert, K. (1999). Aging and language switching in bilinguals. Aging, Neuropsychology, and Cognition, 6, 69-83.

Hinkel, E. (1992). L2 tense and time reference. TESOL Quarterly, 26, 557-572.

Jackson, G. M., Swainson, R., Cunnington, R., \& Jackson, S. R. (2001). ERP correlates of executive control during repeated language switching. Bilingualism: Language and Cognition, 4, 169-178.

Kempen, G., \& Huijbers, P. (1983). The lexicalization process in sentence production and naming: Indirect election of words. Cognition, 14, 185-209.

Kroll, J. F., Bobb, S. C., Misra, M., \& Guo, T. (2008). Language selection in bilingual speech: Evidence for inhibitory process. Acta Psychologica, 128, 416-430.

Lotto, L., \& De Groot, A. M. B. (1998). Effects of learning method and word type on acquiring vocabulary in an unfamiliar language. Language Learning, 48, 31-69.

Meuter, R. F., \& Allport, A. (1999). Bilingual language switching in naming: Asymmetrical costs of language selection. Journal of Memory and Language, 40, 25-40.

Monsell, S., Yeung, N., \& Azuma, R. (2000). Reconfiguration of task set: Is it easier to switch to the weaker task? Psychological Research, 63, 250-264.

Myers-Scotton, C. M. (2005). Supporting a differential access hypothesis: Code switching and other contact data. In J. F. Kroll \& A. M. B. De Groot (Eds.), Handbook of bilingualism: Psycholinguistic approaches (pp. 326-348). New York: Oxford University Press.

Myers-Scotton, C. M. (2006). Natural codeswitching knocks on the laboratory door. Bilingualism: Language and Cognition, 9, 203-212.

Owens, J. (2005). Bare forms and lexical insertions in codeswitching: A processing-based account. Bilingualism: Language and Cognition, 8, 23-38.

Pickering, M. J., \& Branigan, H. P. (1999). Syntactic priming in language production. Trends in Cognitive Sciences, 3, 136-141.

Poplack, S. (1980). Sometimes I'll start a sentence in Spanish y termino en Español: Toward a typology of code-switching. Linguistics, 18, 581-618.

Poulisse, N. (1999). Slips of the tongue: Speech errors in first and second language production. Amsterdam and Philadelphia: John Benjamins.

Quirk, R., Greenbaum, S., Leech, G., \& Svartvik, J. (1985). A comprehensive grammar of the English language. Harlow: Longman.

Santesteban, M. (2006). Lexical representation and selection in bilingual speech production. Unpublished doctoral dissertation. Departament de Psicologia Bàsica, Universitat de Barcelona.

Szekely, A., D’Amico, S., Devescovi, A., Federmeier, K., Herron, D., Iyer, G., Jacobsen, T., Arévalo, A. L., Varghal, A., \& Bates, E. (2002). Timed action and object naming. Cortex, 41, 7-25.

Ullman, M. T. (2001). The neural basis of lexicon and grammar in first and second language: The declarative/procedural model. Bilingualism: Language and Cognition, 4, 105-122.

Wartenburger, I., Heekeren, H. R., Abutalebi, J., Cappa , S. F., Villringer, A., \& Perani, D. (2003). Early setting of grammatical processing in the bilingual brain. Neuron, 37, 159-170.

Wodniecka, Z., Bobb, S. C., Kroll, J. F., \& Green, D. W. (in preparation). Selection processes in bilingual word production: Evidence for inhibition.

Zagorska Brooks, M. (1975). Polish reference grammar. The Hague: Mouton. 